\title{
BMJ Open What is the effect of a decision aid on knowledge, values and preferences for lung cancer screening? An online pre- post study
}

Stephen D Clark (D , ${ }^{1}$ Daniel S Reuland, ${ }^{2}$ Alison T Brenner, ${ }^{2}$ Michael P Pignone ${ }^{3,4}$

To cite: Clark SD, Reuland DS, Brenner AT, et al. What is the effect of a decision aid on knowledge, values and preferences for lung cancer screening? An online pre-post study. BMJ Open 2021;11:e045160. doi:10.1136/ bmjopen-2020-045160

- Prepublication history for this paper is available online. To view these files, please visit the journal online (http://dx.doi. org/10.1136/bmjopen-2020045160).

Received 23 September 2020 Accepted 19 June 2021

Check for updates

(c) Author(s) (or their employer(s)) 2021. Re-use permitted under CC BY-NC. No commercial re-use. See rights and permissions. Published by BMJ.

${ }^{1}$ Division of General Internal Medicine, Virginia Commonwealth University, Richmond, Virginia, USA ${ }^{2}$ Division of General Medicine \& Clinical Epidemiology, Lineberger Comprehensive Cancer Center, University of North Carolina at Chapel Hill School of Medicine, Chapel Hill, North Carolina, USA

${ }^{3}$ Department of Medicine, The University of Texas at Austin Dell Medical School, Austin, Texas, USA

${ }^{4}$ Cancer Institutes, Dell Medical School, LIVESTRONG, Austin, Texas, USA

Correspondence to Dr Stephen D Clark; stephen.clark1@vcuhealth.org

\section{ABSTRACT}

Objective To examine if a decision aid improves knowledge of lung cancer screening benefits and harms and which benefits and harms are most valued.

Design Pre-post study.

Setting Online.

Participants 219 current or former (quit within the previous 15 years) smokers ages 55-80 with at least 30 pack-years of smoking.

Intervention Lung cancer screening video decision aid. Main measures Screening knowledge tested by 10 prepost questions and value of benefits and harms (reducing chance of death from lung cancer, risk of being diagnosed, false positives, biopsies, complications of biopsies and out-of-pocket costs) assessed through rating (1-5 scale) and ranking (top three ranked).

Results Mean age was $64.7 \pm 6.1,42.5 \%$ were male, $75.4 \%$ white, $48.4 \%$ married, $28.9 \%$ with less than a college degree and $67.6 \%$ with income $<$ US $\$ 50000$. Knowledge improved postdecision aid (pre $2.8 \pm 1.8 \mathrm{vs}$ post $5.8 \pm 2.3$, diff $+3.0,95 \% \mathrm{Cl} 2.7$ to $3.3 ; \mathrm{p}<0.001$ ). For values, reducing the chance of death from lung cancer was rated and ranked highest overall (rating 4.3 \pm 1.0 ; $59.4 \%$ ranked first). Among harms, avoiding complications (3.7 \pm 1.3$)$ and out-of-pocket costs $(3.7 \pm 1.2)$ rated highest. Thirty-four per cent ranked one of four harms highest: avoiding costs $13.2 \%$, false positives $7.3 \%$, biopsies $7.3 \%$, complications $5.9 \%$. Screening intent was balanced (1-4 scale; 1 -not likely $21.0 \%$, 4-very likely $26.9 \%$ ). Those 'not likely' to screen had greater improvement in pre-post knowledge scores and more frequently ranked a harm first than those 'very likely' to screen (pre-post diff: +3.5 vs +2.6 , diff $+0.9 ; 95 \% \mathrm{Cl} 0.1$ to $1.8 ; p=0.023$; one of four harms ranked first: $28.4 \%$ vs $11.3 \%, p<0.001$ ). Conclusions Our decision aid increased lung cancer screening knowledge among a diverse sample of screen-eligible respondents. Although a majority valued 'reducing the chance of death from lung cancer' highest, a substantial proportion identified harms as most important. Knowledge improvement and ranking harms highest were associated with lower intention to screen.

\section{INTRODUCTION}

The US Preventive Service Task Force (USPSTF) and other national organisations recommend offering lung cancer screening
Strengths and limitations of this study

- Lung cancer screening knowledge of benefit and harms, valuing of benefit and harms, and screening intention could be examined across diverse participants.

- Use of a high-quality video decision aid.

- Information limited to the decision aid: individuals were not able to have a shared decision-making discussion with their provider to inform their responses.

- Screening intention may not reflect actual screening behaviour.

- Our sample population was more educated and more white overall than the general lung cancer screening eligible population.

with low-dose CT (LDCT) to high-risk individuals. ${ }^{1-4}$ Because of the need to balance potential benefits in reducing lung cancer deaths against potential harms, including overdiagnosis and the need for additional imaging and biopsies, guidelines emphasise the need for shared decision making. Shared decision making aims to assist an individual in coming to a screening decision "while incorporating the available evidence on the potential harms and benefits of the test with pertinent patients values and preferences. ${ }^{, 5}$ The American Thoracic Society (ATS) and American College of Chest Physicians (ACCP) stress that discussions should help individuals "make informed choices about whether LDCT screening is right for them. ${ }^{6}$ Accumulating evidence suggests that decision aids could improve these discussions by increasing knowledge and clarifying values. ${ }^{7-12}$

Accurate knowledge of screening tests by individuals considering testing is essential for high quality shared decision making. In an effort to ensure individuals are informed regarding lung cancer screening, the Centers for Medicare \& Medicaid Services (CMS) requires decision aid use to obtain screening 
reimbursement for Medicare beneficiaries. ${ }^{13}$ Further, CMS requires that decision aids address specific potential harms. For example, one potential harm is overdiagnosis, the detection of a cancer that would not have otherwise been discovered or caused symptoms during the individual's lifetime. This potential harm can lead to unnecessary treatment of the cancer, which includes surgery, radiation and/or chemotherapy as well the psychological consequences of a cancer diagnosis. As with other harms, the concept of overdiagnosis is difficult for individuals and providers. ${ }^{14-19}$ The difficulty for this harm is, in part, due to the fact that the phenomenon of overdiagnosis becomes evident only in retrospect and at the population level. Thus, we cannot know whether any individual cancer is overdiagnosed. Two small studies ( $\mathrm{n}=50$ and $n=52$ ) examined knowledge of lung cancer screening benefits and harms before and after viewing a decision aid. These studies demonstrated low baseline knowledge among eligible individuals but an increased overall knowledge after exposure to a decision aid. In one study, the mean baseline percentage correct for seven questions was $26.0 \%$ improving to $59.1 \%$ after the decision aid and the other study showed a baseline percentage correct for one question of $48.1 \%$ improving to $88.5 \% .^{10}{ }^{12}$ The studies were small in size, however, with limited power to examine demographic differences.

After gaining knowledge of lung cancer screening, individuals must also consider the value they place on the specific benefits and harms when making their screening decision, and providers must understand an individuals' values to facilitate value-concordant decisions. The ACCP and ATS emphasise that providers 'be capable of helping their patients make value-based decisions about screening,' but little is known regarding what benefits and harms screen-eligible individuals value when considering screening. ${ }^{20}$ One study $(n=588)$ at a single Veterans Affairs Health Care System found individuals rated 'fear of getting lung cancer' as important most often $(43 \%)$ but about a quarter to a third of respondents rated each of three harms choices (false positives, incidental findings, and radiation) important as well. ${ }^{21}$ However, these values were assessed by mailed survey in an overwhelmingly white male population of military veterans months after they had been mailed a brochure about screening and had already chosen to undergo screening or not. Hence, further study is needed in a broader population after viewing a decision aid to assess how benefits and harms are valued against one another.

Our study sought to evaluate the ability of a lung cancer screening decision aid to improve knowledge of lung cancer screening in a larger sample to facilitate more in depth comparisons, to determine what benefits and harms these individuals value most when considering screening, and to examine the relationships between knowledge, values and screening intentions.

\section{METHODS}

\section{Survey sample}

We recruited US respondents through online panels using Qualtrics, a national survey company. ${ }^{22}$ Individuals in these panels agree to receive survey invitations. Email invitations were sent to individuals 55-80 years old with a smoking history. The survey contained initial questions to identify those meeting USPSTF criteria for lung cancer screening. Those meeting criteria (current or former smoker who quit within 15 years; 30 pack-year history minimum) could continue. Initial questions also ensured that quotas to include at least $20 \%$ of respondents were Black/African American or Hispanic/Latino and at least $25 \%$ had less than college education were met. We also asked additional demographics questions on income, health insurance and relationship status. All survey items were contained within one survey for respondents to complete in one sitting. Consent was obtained from respondents by their agreeing to proceed with the online survey after being presented with information about the study.

\section{Patient decision aid and pre-post knowledge questions}

We used a previously tested video-based decision aid on lung cancer screening, modified for the on-line survey context, to inform respondents. ${ }^{1023}$ The three and a half minute decision aid focused on the harms and benefits of screening for lung cancer based on evidence from the high-risk population studied in the National Lung Screening Trial. ${ }^{24}$

The benefits and harms were based on those outlined in the USPSTF recommendation statement and CMS. ${ }^{132}$ Prior to viewing the decision aid, respondents completed ten knowledge-based questions (table 1). Nine of these questions had been tested in previous work. ${ }^{10}$ We added one new question on the expected number of diagnoses of lung cancer out of 1000 patients screened to provide context for respondent answers about lives saved and cancers overdiagnosed. Of the 10 questions, seven focused on conceptual knowledge of overdiagnosis, which were adapted from a previously published scale. ${ }^{26}$ Three questions assessed individual understanding of the approximate magnitude of benefit and overdiagnosis of screening. For these questions, we considered responses that included the correct numerical value as well as for the numerical ranges within an order of magnitude to be correct.

\section{Rating, ranking screening intent}

After completing the knowledge questions and viewing the decision aid, respondents were asked to rate six attributes (benefit and harms) of lung cancer screening. Attributes were based on formative work, our own prior research, and a review of the literature. ${ }^{102728}$ The potential screening benefit was represented as reducing the chance of death from lung cancer (mortality benefit). The harms were represented by: reducing the risk of diagnosis of lung cancer (overdiagnosis); avoiding CT 


\section{Table 1 Survey items}

$\begin{array}{ll}\text { Pre-post } & \text { Who do you think is more likely to be diagnosed with lung cancer in their lifetime? } \\ \text { questions and } & \text { People who get screened } / \text { People are equally likely to be diagnosed/People who do NOT get screened }\end{array}$

All lung cancers will eventually cause illness and death if they are not found and treated. True/False*/Don't know

When screening finds cancer, doctors can tell whether it will ever cause harm.

True/False*/Don't know

Even lung cancers that may not cause any health problems are likely to be treated.
True*/False/Don't know

Screening tests find harmless lung cancers about as often as they prevent death from lung cancer. True*/False/Don't know

Which of these two statements best describes over-detection from screening?
Screening finds an abnormality but extra tests show it is not cancer/ Screening finds a cancer that would
never have caused trouble*

Out of 1000 people like you who get a low-dose CT scan yearly for 3 years, about how many will be diagnosed with lung cancer?

None/Very few (1-10)/Few (11-30)/Some (31-200*/Many (201-500)/Most (501-1000)/Don't know

Out of 1000 people like you who get a low-dose CT scan yearly for 3 years, about how many will have their lives prolonged from lung cancer screening?

None/Very few (1-10)*/Few (11-30)*/Some (31-200)/Many (201-500)/Most (501-1000)/Don't know

Out of 1000 people like you who get a low dose CT scan yearly for 3 years, about how many will be diagnosed with cancer that would not have needed treatment?

None/Very few (1-10)*/Few (11-30)*/Some (31-200)/Many (201-500)/Most (501-1000)/Don't know

\begin{tabular}{ll}
$\begin{array}{l}\text { Benefit and harms } \\
\text { attributes }\end{array}$ & Reduce the chance of death from lung cancer \\
& Avoiding CT scans that do not find cancer, including false alarms \\
& Avoiding biopsies that do not find cancer \\
& Avoiding complications of biopsies \\
& Reduce risk of diagnosis with lung cancer \\
& Avoiding chances of high out of pocket costs for additional scans, biopsies and complications \\
\hline $\begin{array}{l}\text { Screening intent } \\
\text { item }\end{array}$ & After viewing the video, how likely are you to get screened for lung cancer? (1-not likely, 2, 3, 4-very likely)
\end{tabular}

${ }^{*}$ Correct answer(s).

scans that do not find cancer, including false alarms (false positives); avoiding biopsies that do not find cancer (procedures of false positives); avoiding complications of biopsies (complications of biopsies); avoiding chances of high out of pocket costs for additional scans, biopsies and complications (extra cost to individuals). Rating was conducted on a 1-5 scale (1-least important, 5-most important). The question stem for rating was: 'Please rate the importance of the following statements to you when considering lung cancer screening.' Respondents ranked their top three attributes in order of importance, prompted by the question stem: 'Please rank the three most important statements to you when considering lung cancer screening.' Finally, after viewing the decision aid and completing knowledge, rating and ranking tasks, respondents completed a question on screening intent: 'After viewing the video, how likely are you to get screened for lung cancer?' Answer choices were on a scale of 1-4 with one being 'not likely' and four being 'very likely.'

\section{Statistical analysis}

We sought a sample of at least 200 in order to perform comparisons among different demographic subgroups. This sample size was chosen based on feasibility and the aim to examine differences within subgroups of race and education level. After describing the study sample, we compared mean prescores and postscores for each question with McNemar's $\chi^{2}$ test and overall mean prescores and postscores with a paired t-test. We used descriptive statistics to analyse rating, ranking and screening intention. To evaluate differences between demographic groups in regards to knowledge, rating, ranking and screening intent, we used unpaired t-tests. We used Pearson's $\chi^{2}$ tests to compare top ranked attributes by screening intention groups. We conducted multivariable analysis with linear and logistic regression to test for differences in knowledge, rating, ranking and screening intent adjusting for demographic groups (sex, race, education, income and marriage status). Demographics for comparisons were 
chosen a priori as they were hypothesised to influence knowledge, rating/ranking and screening intent. For regression analysis, we dichotomised/collapsed variables as follows for each of the analyses: age $(<65$ or $\geq 65$ years old), income ( $<$ US $\$ 50000$ or $\geq U S \$ 50000)$, education (at least some college vs no college), marriage (married or unmarried, which included widowed and divorced individuals), race (white, black/African-American, Hispanic/ Latino). Our analysis included only data from those respondents who completed the entire survey. Statistical analysis was carried out with Stata, release15 (StataCorp LLC).

\section{Patient and public involvement statement}

Patients and the public were not involved in the design or completion of this study.

\section{RESULTS}

We sent the survey invitation to 2195 individuals and $1135(51.7 \%)$ responded to the eligibility questions. After excluding respondents based on USPSTF eligibility criteria and race/education quotas, 255 were advanced to begin the full survey and $219(85.8 \%)$ completed it. Of those completing the survey, respondents had an average age of $64.7 \pm 6.1$ with $93(42.5 \%)$ being male, $165(75.4 \%)$ white, $106(48.4 \%)$ married, $147(67.1 \%)$ current smokers, $62(28.9 \%)$ with less than a college degree and $148(67.6 \%)$ with income less than US\$50 000 (table 2).

\section{Screening knowledge}

Respondents had a low mean baseline knowledge score of $2.7 \pm 1.7$ out of 10 possible correct answers on the survey items testing knowledge. Following decision aid viewing, the mean score increased to $5.8 \pm 2.3$ (mean diff +3.0 , $95 \%$ CI 2.7 to $3.3, \mathrm{p}<0.001)$. There was no difference in the amount of change in pre-post knowledge score between demographic groups for both our unadjusted and adjusted analyses.

We found a significant pre-post increase in correct responses in nine of ten items (table 3). Proportions of respondents able to correctly identify the likelihood of benefiting from screening increased after decision aid viewing (pre $16.4 \%$ vs post $38.4 \%, \mathrm{p}<0.001$ ), as did the proportion who accurately estimated the likelihood of being overdiagnosed with screening $(24.7 \%$ vs $46.1 \%$, $\mathrm{p}<0.001)$.

\section{Rating and ranking}

Rating

Among attributes, 'reducing the chance of death from lung

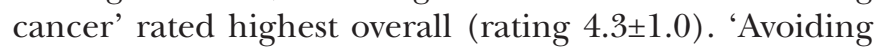
complications of biopsies' $(3.7 \pm 1.3)$ and 'avoiding outof-pocket costs' $(3.7 \pm 1.2)$ rated higher than other harms attributes (table 4). Black/African-American respondents were more likely to rate 'reducing the chance of diagnosis' higher than whites ( 4.0 vs 3.5 , diff $+0.5,95 \%$ CI 0.1 to 0.9 ; $\mathrm{p}=0.02$ ). The difference remained after adjustment for
Table 2 Demographic characteristics of online survey respondents eligible for lung cancer screening $(n=219)$

\begin{tabular}{ll}
\hline & Total $(\mathbf{n}=\mathbf{2 1 9})$ \\
\hline & $\mathbf{n}(\%)$ or mean (SD) \\
\hline $\begin{array}{l}\text { Sex (male) mean (SD) } \\
\text { Age mean (SD) }\end{array}$ & $93(42.5)$ \\
Race & $64.7(6.1)$ \\
White & $165(75.4)$ \\
Black or African-American & $38(17.4)$ \\
Hispanic or Latino & $13(5.9)$ \\
Other & $3(1.4)$
\end{tabular}

Relationship status

\begin{tabular}{|c|c|}
\hline Married & $106(48.4)$ \\
\hline Divorced & $51(23.3)$ \\
\hline Separated & $4(1.8)$ \\
\hline Widowed & $25(11.4)$ \\
\hline Never married & $24(11.0)$ \\
\hline Member of an unmarried couple & $9(4.1)$ \\
\hline \multicolumn{2}{|l|}{ Highest education level } \\
\hline Completed college & $49(22.4)$ \\
\hline Some college or technical school & $108(49.3)$ \\
\hline Completed high school or GED & $55(25.1)$ \\
\hline Some high school & 7 (3.2) \\
\hline \multicolumn{2}{|l|}{ Annual Income } \\
\hline Less than US\$10K & $9(4.1)$ \\
\hline Less than US\$25K, $\geq$ US $\$ 10 \mathrm{k}$ & $59(26.9)$ \\
\hline Less than US\$50K, $\geq 25 \mathrm{~K}$ & 72 (32.9) \\
\hline Less than US $\$ 75 \mathrm{~K}, \geq 50 \mathrm{~K}$ & $34(15.5)$ \\
\hline Less than US\$125K, $\geq 75 \mathrm{~K}$ & $21(9.6)$ \\
\hline Greater than US\$125K & $16(7.3)$ \\
\hline Prefer not to answer & $8(3.7)$ \\
\hline \multicolumn{2}{|l|}{ Health insurance } \\
\hline Private & $44(20.1)$ \\
\hline Medicare & $128(58.5)$ \\
\hline Medicaid & $24(11.0)$ \\
\hline Military & 7 (3.2) \\
\hline Other & $5(2.3)$ \\
\hline No coverage & $11(5.0)$ \\
\hline Smoking status & $147(67.1)$ \\
\hline Current & $147(67.1)$ \\
\hline Former & $72(32.8)$ \\
\hline \multicolumn{2}{|l|}{ Pack-years of smoking } \\
\hline Current mean (SD)/median & $47.2(17.2) / 44.0$ \\
\hline Former mean (SD)/median & $63.1(30.1) / 52.2$ \\
\hline
\end{tabular}

GED, General Educational Development. 
Table 3 Changes in lung cancer screening knowledge before and after viewing the decision aid $(n=219)$

\begin{tabular}{|c|c|c|c|c|}
\hline Question & $\begin{array}{l}\text { Pre, correct } \\
\text { answer } \\
\text { n (\%) }\end{array}$ & $\begin{array}{l}\text { Post, correct } \\
\text { answer } \\
\text { n (\%) }\end{array}$ & $\begin{array}{l}\text { Difference } \\
\text { n (\%) }\end{array}$ & $P$ value \\
\hline $\begin{array}{l}\text { Who do you think is more likely to be diagnosed with lung cancer in } \\
\text { their lifetime? } \\
\text { People who get screened*/People are equally likely to be diagnosed/ } \\
\text { People who do NOT get screened }\end{array}$ & 39 (17.8) & 79 (36.1) & $40(+18.3)$ & $<0.001$ \\
\hline $\begin{array}{l}\text { When screening finds cancer, doctors can tell whether it will ever } \\
\text { cause harm. } \\
\text { True/False*/Don't know }\end{array}$ & $44(20.1)$ & $142(64.8)$ & $98(+44.7)$ & $<0.001$ \\
\hline $\begin{array}{l}\text { Even lung cancers that may not cause any health problems are likely } \\
\text { to be treated. } \\
\text { True*/False/Don't know }\end{array}$ & $161(73.5)$ & $171(78.1)$ & $10(+4.6)$ & 0.21 \\
\hline $\begin{array}{l}\text { Screening tests find harmless lung cancers about as often as they } \\
\text { prevent death from lung cancer. } \\
\text { True*/False/Don't know }\end{array}$ & 69 (31.5) & $125(57.1)$ & $56(+25.6)$ & $<0.001$ \\
\hline $\begin{array}{l}\text { Which of these two statements best describes over-detection from } \\
\text { screening? } \\
\text { Screening finds an abnormality but extra tests show it is not cancer/ } \\
\text { Screening finds a cancer that would never have caused trouble* }\end{array}$ & 38 (17.4) & $66(30.1)$ & $28(+12.7)$ & $<0.01$ \\
\hline $\begin{array}{l}\text { Out of } 1000 \text { people like you who get a low dose CT scan yearly for } \\
3 \text { years, about how many will be diagnosed with lung cancer? } \\
\text { None/Very few (1-10)/Few }(11-30)^{\star} / \text { Some }(31-200)^{\star} / \text { Many }(201-500) / \\
\text { Most (501-1000)/Don't know }\end{array}$ & 85 (38.8) & $125(57.1)$ & $40(+18.3)$ & $<0.001$ \\
\hline $\begin{array}{l}\text { Out of } 1000 \text { people like you who get a low dose CT scan yearly for } \\
3 \text { years, about how many will be diagnosed with cancer that would } \\
\text { not have needed treatment? } \\
\text { None/Very few }(1-10)^{\star} / \text { Few }(11-30)^{\star} / \text { Some }(31-200) / \text { Many }(201-500) / \\
\text { Most }(501-1000) / \text { Don't know }\end{array}$ & $54(24.7)$ & $101(46.1)$ & $47(+21.4)$ & $<0.001$ \\
\hline
\end{tabular}

${ }^{*}$ Correct answer(s).

Table 4 Rating/ranking of lung cancer screening attributes $(n=219)$

\begin{tabular}{llll}
\hline & $\begin{array}{l}\text { Rating } \\
\text { mean (SD) }\end{array}$ & $\begin{array}{l}\text { Total first ranks } \\
\mathbf{n}(\%)\end{array}$ & $\begin{array}{l}\text { Total ranks (1st-3rd) } \\
\mathbf{n}(\% \text { of 657 possible) }\end{array}$ \\
\hline $\begin{array}{l}\text { Reduce the chance of death from lung cancer } \\
\begin{array}{l}\text { Avoiding chances of high out of pocket costs for additional scans, } \\
\text { biopsies and complications }\end{array}\end{array}$ & $\begin{array}{l}4.3(1.0) \\
130(59.4)\end{array}$ & $174(26.5)$ \\
$\begin{array}{l}\text { Avoiding complications of biopsies } \\
\text { Reduce risk of diagnosis with lung cancer }\end{array}$ & $3.7(1.3)$ & $13(5.9)$ & $101(15.3)$ \\
Avoiding biopsies that do not find cancer & $3.6(1.4)$ & $15(6.8)$ & $94(14.3)$ \\
Avoiding CT scans that do not find cancer, including false alarms & $3.3(1.2)$ & $16(7.3)$ & $98(14.9)$ \\
\hline
\end{tabular}


demographic characteristics. Females were more likely to rate 'reducing the chance of diagnosis' higher than males (3.8 vs 3.4, diff $+0.4,95 \%$ CI 0.05 to $0.7 ; \mathrm{p}=0.02$ ), but this difference did not remain after adjustment. Those with an income less than US\$50000 rated avoiding false positives higher than those with incomes US $\$ 50000$ or greater (3.4 vs 3.1 , diff $+0.3,95 \%$ CI 0.01 to $0.7 ; p=0.02$ ) and those who were unmarried rated avoiding false positives higher than those who were married (3.5 vs 3.1, diff $+0.4,95 \%$ CI 0.02 to $0.6, \mathrm{p}=0.04)$. However, neither remained after adjustment. There were no other demographic differences among ratings.

\section{Ranking}

Fifty-nine per cent $(n=130)$ ranked the benefit of 'reducing chance of death from lung cancer' as the most important attribute compared with $33.7 \% \quad(n=89)$ who ranked avoiding one of four harms (avoiding false positives, avoiding biopsies, avoiding complications of biopsies and avoiding chances of high out of pocket costs) as most important to their decision. Individual harms rankings were heterogeneous (avoiding costs 13.2\%, false positives $7.3 \%$, biopsies $7.3 \%$, complications of biopsies $5.9 \%$ ) and $6.8 \%$ ranked 'reducing the chance of diagnosis' first.

Those 65 years and older were more likely to rank 'reducing the chance of death' first compared with those younger than $65(67.0 \%$ vs $51.4 \%, \mathrm{p}=0.02)$. Those identifying as black/African-American were more likely to rank 'reducing the chance of diagnosis' first compared with whites $(18.8 \%$ vs $5.1 \%, \mathrm{p}=0.02)$. These differences remained after adjustment. Hispanic/Latino more likely than whites to rank 'avoiding false positives' first $(30.0 \%$ vs $7.1 \%, \mathrm{p}=0.03$ ), but this difference did not remain after adjustment.

\section{Screening intention}

Screening intentions assessed after the decision aid were relatively evenly distributed across the four response choices: $46(21.0 \%)$ responded 1-not likely, 49 (22.4\%) responded 2, $65(29.7 \%)$ responded 3, and 59 (26.9\%) responded 4-very likely. There were no differences between demographic groups on bivariate analysis, but after adjustment for demographic characteristics; those who were unmarried more frequently indicated that they were 'very likely' to purse screening compared with married individuals (OR 2.8, 95\% CI 1.1 to 7.4).

\section{Associations between knowledge and screening intention}

Comparing those 'not likely' to screen versus those 'very likely' to screen, there were no differences in predecision or postdecision aid knowledge scores. Individuals indicating they were 'not likely' to pursue screening, however, were more likely to have had a greater improvement in pre-post knowledge score than those indicating that they were 'very likely' to pursue screening $(+3.5 \mathrm{vs}+2.6$, diff $+0.9 ; 95 \%$ CI 0.1 to $1.8 ; \mathrm{p}=0.023)$. This difference remained after adjustment for demographic characteristics.

\section{Associations between values and screening intention}

Those indicating they were 'very likely' to screen were more likely to have a higher mean rating for 'reducing the chance of death from lung cancer' than those 'not likely' to screen ( 4.9 vs 3.5 , diff +1.4 ; $95 \%$ CI 1.1 to 1.7 ; $\mathrm{p}<0.001$ ) (table 5). 'Reducing the risk of diagnosis with lung cancer' was also more likely to be rated higher by those 'very likely' to screen ( 4.1 vs 3.3 , diff $0.7 ; 95 \%$ CI 0.3 to $1.2 ; \mathrm{p}=0.001$ ), suggesting that respondents may not have recognised that screening increases the risk of being diagnosed. These differences remained after adjustment. Rating of the other harms attributes had no significant associations with screening intention.

Of those ranking 'reducing the chance of death from lung cancer' as their top attribute, respondents were more likely to report being 'very likely' to screen compared with 'not likely' to screen $(39.0 \%$ vs $16.2 \%, \mathrm{p}=0.001)$. Those ranking any of four harms attributes (avoiding false positives, biopsies, complications or out-of-pocket costs) first more often indicated that they were 'not likely' to screen compared with 'very likely' to screen $(24.8 \%$ vs $11.3 \%$, $\mathrm{p}<0.001)$. Respondents who ranked the individual harms attributes of 'avoiding CT scans that do not find cancer',

Table 5 Rating and ranking attribute by intent to screen $(n=105)$

\begin{tabular}{lllllll}
\hline & Not likely & Very likely & & Not likely & Very likely \\
\hline & $\begin{array}{l}\text { Rating } \\
\text { Mean (SD) }\end{array}$ & $\begin{array}{l}\text { Rating } \\
\text { Mean (SD) }\end{array}$ & $\begin{array}{l}\text { P } \\
\text { value }\end{array}$ & $\begin{array}{l}\text { \% ranked } \\
\text { first }\end{array}$ & $\begin{array}{l}\text { \% ranked } \\
\text { first }\end{array}$ & P value \\
\hline $\begin{array}{l}\text { Reduce the chance of death from lung cancer } \\
\text { Reduce risk of diagnosis with lung cancer }\end{array}$ & $3.5(1.2)$ & $4.9(0.3)$ & $<0.001$ & 16.2 & 39.0 & $<0.01$ \\
\hline $\begin{array}{l}\text { Avoiding CT scans that do not find cancer, including false } \\
\text { alarms }\end{array}$ & $3.3(1.2)$ & $4.1(1.1)$ & $<0.01$ & 2.9 & 5.7 & 0.51 \\
\hline $\begin{array}{l}\text { Avoiding biopsies that do not find cancer } \\
\text { Avoiding complications of biopsies }\end{array}$ & $3.3(1.3)$ & 0.45 & 9.5 & 1.0 & $<0.01$ \\
$\begin{array}{l}\text { Avoiding chances of high out of pocket costs for } \\
\text { additional scans, biopsies and complications }\end{array}$ & $3.9(1.2)$ & $3.4(1.4)$ & 0.18 & 3.8 & 1.0 & 0.17 \\
\hline
\end{tabular}

*Statistical significance did not remain after adjustment for age, sex, education, race and income. 
including false alarms $(9.5 \%$ vs $1.0 \%, \mathrm{p}=0.001)$, as most important were more likely to indicate a screening intention of 'not likely' compared with 'very likely,' which remained after adjustment. Those ranking 'avoiding complications of biopsies' ( $5.7 \%$ vs $1.0 \%, \mathrm{p}=0.021$ ) first more frequently indicated being 'not likely' to pursue screening, but this difference did not remain after adjustment. There were no other significant differences found in screening intent among other attributes.

\section{DISCUSSION}

Our decision aid improved knowledge about lung cancer screening in a diverse sample. It was also able to improve the accuracy of perceived likelihood of benefit among screen-eligible individuals. Although a majority valued the potential benefit of reducing risk of death from lung cancer, a substantial proportion valued harm avoidance. This study also found that screening intent was relatively evenly distributed and generally consistent with what individuals indicated was important to them, that is, avoiding harms or gaining benefit.

Our main findings mirror the mean pre-post knowledge increase seen in our previous, smaller study. ${ }^{10} \mathrm{We}$ found similar low baseline levels of knowledge and similar improvements after viewing the decision aid. Knowledge of overdiagnosis increased, despite the potential harm being a difficult concept for individuals and providers alike. ${ }^{14-19}$ However, knowledge increases were moderate, pointing toward the challenges in informed decision making. In this larger study, we were able to extend our findings to show that improvements in knowledge were similar across demographic subgroups. These data add to the limited body of evidence showing that a brief, videobased lung cancer screening decision aid can improve knowledge about screening and overdiagnosis, including in black/African-American and Hispanic/Latino populations. A lack of knowledge regarding screening tests has led to screening disparities in screening for other cancers and the use of decision aids, such as the one used in this study, may help reduce those disparities. ${ }^{29-31}$

We found that a majority of individuals valued the benefit of lung cancer screening (reducing the chance of death) as most important; however, a substantial proportion $(33.7 \%)$ identified one of four harms of screening (avoiding false positives, biopsies, complications or outof-pocket costs) as their most important attribute. The statement for the fifth harm attribute representing overdiagnosis (reduce the risk of diagnosis), may not have been understood as intended. Despite an increase in conceptual overdiagnosis knowledge in the pre-post questions (eg, that 'screening leads some people with a harmless cancer to get treatment they do not need'), it is unclear if respondents viewed an increased chance of being diagnosed with lung cancer as a harm or if they assumed it to mean earlier diagnosis and hence a benefit. Those rating the importance of this harm higher more often indicated they were 'very likely' to screen than 'not likely,' indirectly suggesting respondents viewed it as a benefit rather than a harm.

Of the harms attributes, avoiding high out-of-pocket costs most often ranked the highest. This adds to a limited but growing evidence about individual perceptions of the potential harm of out-of-pocket costs after the initial screening CT. Major guidelines do not include this as a talking point during the shared decision-making discussion. ${ }^{2-42532}$ In the USA, CT for lung cancer screening is usually covered $100 \%$ by insurance, including Medicare. However, following up testing, which may include additional imaging, biopsies and surgical resection may not be fully covered by insurance providers and uninsured patients would be subject to full costs. A previous study found concern for the cost of screening to be a potential barrier to initiating lung cancer screening and a more recent study found out-of-pocket costs to have the highest relative importance among eligible individuals compared with other aspects of screening, including mortality benefit. ${ }^{33}$ Our results support these findings that cost may play an important role in individuals' decisions about healthcare interventions. Providers may need to explicitly discuss the potential for out-of-pocket costs, rather than simply stating that 'screening is covered' by insurance providers, as was observed in a study of patientprovider lung cancer screening discussions. ${ }^{35}$ Policy-makers could consider requiring full coverage for at least part of the downstream cascade of screening, such as follow-up scans for lung nodules.

The heterogeneity of intention to pursue lung cancer screening after viewing a decision aid across our screeneligible sample mirrors the findings from two previous studies. ${ }^{10} 36$ Those with greater change in knowledge scores and those ranking a harm first more often were 'not likely' to screen. This is similar to others studies that have found lower intent to screen for those with higher rating, recognition or knowledge of harms. ${ }^{10} 2132$ These findings suggest that a substantial number (though probably still a minority) of screen-eligible individuals may not wish to pursue screening when fully informed of the potential benefits and harms. This finding may have important implications for continued discussion and study of the optimal timing of shared decision making, since heterogeneity in preferences for or against screening is observed when the decision support is delivered right when screening is initially offered, and screening is presented as a decision with tradeoffs. In contrast, screening preferences appear to be highly homogeneous (in favour of screening) in populations that receive decision support after being referred to lung cancer screening clinics, suggesting that their decision may have already been made. ${ }^{8}$

Our study has limitations. First, our sample is somewhat more educated and white than the general USPSTF-eligible population for lung cancer screening. However, our sample was more racially diverse and was similarly educated to the NLST (National Lung Screening Trial) sample. ${ }^{37}$ Second, our study was delivered online. The effort of respondents is unclear, however, these findings regarding knowledge and screening intentions mirrored a similar clinic-based study. ${ }^{10}$ 
Third, in order to reduce survey burden, we did not include all possible harms of screening (radiation, incidental findings, psychological harms, etc) in our attributes. Fourth, some respondents appeared not to have understood the overdiagnosis attribute as worded, pointing to the need for additional studies aimed at understanding the importance of this screening harm and how to communicate it to individuals facing a screening decision. Finally, screening intention may not capture an actual action in a healthcare setting, though self-reported intent is predictive of (and a common proxy for) screening behaviour.

\section{CONCLUSIONS}

This study provides further evidence that decision aids for lung cancer screening can improve knowledge of benefits and harms, particularly overdiagnosis, across demographic groups. Screen-eligible individuals most often ranked 'reducing the chance of death from lung cancer,' as most important but over a third ranked a potential harm highest. The valuing of the benefit or a harm as most important, measured through ranking, generally aligned with intention to pursue or not pursue lung cancer screening as expected, and support the importance of shared decision making in lung cancer screening.

Contributors SDC, DSR, ATB and MPP contributed to the design of the work, analysis and interpretation of the data, editing of the manuscript, gave final approval of the manuscript and are in agreement to be accountable for all aspects of the work. SC was also responsible for the acquisition of data and initial drafting of the manuscript. DSR and MPP contributed equally as senior authors.

Funding SDC's time was supported by the Health Resources and Services Administration funded primary care research fellowship at the University of North Carolina at Chapel Hill (T32-HP14001).

Competing interests SDC was funded through the Health Resources and Services Administration T32-HP14001. DSR was supported through the University Cancer Research Fund of the Lineberger Comprehensive Cancer Center at the University of North Carolina at Chapel Hill. The authors have no other disclosures.

Patient and public involvement Patients and/or the public were not involved in the design, or conduct, or reporting, or dissemination plans of this research.

Patient consent for publication Not required.

Ethics approval The Institutional Review Board at the University of North Carolina at Chapel Hill deemed our study (ID 19-0767) exempt as it did not collect any identifiable information from participants and the risk to participants was deemed low.

Provenance and peer review Not commissioned; externally peer reviewed.

Data availability statement № data are available.

Open access This is an open access article distributed in accordance with the Creative Commons Attribution Non Commercial (CC BY-NC 4.0) license, which permits others to distribute, remix, adapt, build upon this work non-commercially, and license their derivative works on different terms, provided the original work is properly cited, appropriate credit is given, any changes made indicated, and the use is non-commercial. See: http://creativecommons.org/licenses/by-nc/4.0/.

\section{ORCID iD}

Stephen D Clark http://orcid.org/0000-0003-4830-0531

\section{REFERENCES}

1 Moyer VA, U.S. Preventive Services Task Force. Screening for lung cancer: U.S. preventive services Task force recommendation statement. Ann Intern Med 2014;160:330-8.
2 Mazzone PJ, Silvestri GA, Patel S, et al. Screening for lung cancer: chest guideline and expert panel report. Chest 2018;153:954-85.

3 Smith RA, Andrews KS, Brooks D, et al. Cancer screening in the United States, 2018: a review of current American cancer Society guidelines and current issues in cancer screening. CA Cancer J Clin 2018;68:297-316.

4 Kumar R, Reddy C, Kazerooni EA. Lung cancer screening, version 3.2018, NCCN clinical practice guidelines in oncology. J Natl Compr Cancer Netw 2018;16:412-41.

5 Tanner NT, Silvestri GA. Shared decision-making and lung cancer screening: let's get the conversation started. Chest 2019;155:21-4.

6 Wiener RS, Gould MK, Arenberg DA, et al. An official American thoracic Society/American College of chest physicians policy statement: implementation of low-dose computed tomography lung cancer screening programs in clinical practice. Am J Respir Crit Care Med 2015;192:881-91.

7 Stacey D, Légaré F, Lewis $\mathrm{K}$, et al. Decision AIDS for people facing health treatment or screening decisions. Cochrane Database Syst Rev 2017;19.

8 Mazzone PJ, Tenenbaum A, Seeley M, et al. Impact of a lung cancer screening counseling and shared decision-making visit. Chest 2017;151:572-8.

9 Lau YK, Caverly TJ, Cao P, et al. Evaluation of a personalized, web-based decision aid for lung cancer screening. Am J Prev Med 2015;49:e125-9.

10 Reuland DS, Cubillos L, Brenner AT, et al. A pre-post study testing a lung cancer screening decision aid in primary care. BMC Med Inform Decis Mak 2018;18:5.

11 Huo J, Shen C, Volk RJ, et al. Use of CT and chest radiography for lung cancer screening before and after publication of screening guidelines: intended and unintended uptake. JAMA Intern Med 2017;177:439.

12 Volk RJ, Linder SK, Leal VB, et al. Feasibility of a patient decision aid about lung cancer screening with low-dose computed tomography. Prev Med 2014;62:60-3.

13 Centers for Medicare \& Medicaid Services. Decision MEMO for screening for lung cancer with low dose computed tomography (LDCT), 2015. Available: https://www.cms.gov/medicare-coveragedatabase/details/nca-decision-memo.aspx?NCAld=274

14 Parker LM, Rychetnik L, Carter S. Framing overdiagnosis in breast screening: a qualitative study with Australian experts. BMC Cancer 2015;15:606.

15 Nickel B, Brito JP, Barratt A, et al. Clinicians' views on management and terminology for papillary thyroid microcarcinoma: a qualitative study. Thyroid 2017;27:661-71.

16 Park SH, Lee B, Lee S, et al. A qualitative study of women's views on overdiagnosis and screening for thyroid cancer in Korea. BMC Cancer 2015;15.

17 Nagler RH, Franklin Fowler E, Gollust SE. Women's awareness of and responses to messages about breast cancer overdiagnosis and overtreatment. Med Care 2017;55:879-85.

18 Hersch J, Jansen J, Barratt A, et al. Women's views on overdiagnosis in breast cancer screening: a qualitative study. BMJ 2013;346:f158.

19 Moynihan R, Sims R, Hersch J, et al. Communicating about overdiagnosis: learning from community focus groups on osteoporosis. PLoS One 2017;12:e0170142.

20 Mazzone P, Powell CA, Arenberg D, et al. Components necessary for high-quality lung cancer screening: American College of chest physicians and American thoracic Society policy statement. Chest 2015;147:295-303.

21 Lillie SE, Fu SS, Fabbrini AE, et al. What factors do patients consider most important in making lung cancer screening decisions? findings from a demonstration project conducted in the Veterans health administration. Lung Cancer 2017;104:38-44.

22 Qualtrics. Qualtrics, 2019. Available: https://www.qualtrics.com/

23 Clark SD, Reuland DS, Brenner AT, et al. Harms and benefits of lung cancer screening, 2019. Available: https://www.youtube.com/watch? $\mathrm{v}=\mathrm{kNN}$ T-OWKPw

24 National Lung Screening Trial Research Team, Aberle DR, Adams AM, et al. Reduced lung-cancer mortality with low-dose computed tomographic screening. N Engl J Med 2011;365:395-409.

25 Moyer VA, U.S. Preventive Services Task Force. Screening for lung cancer: U.S. preventive services Task force recommendation statement. Ann Intern Med 2014;160:330-338-8.

26 Hersch J, Barratt A, Jansen J, et al. Use of a decision aid including information on overdetection to support informed choice about breast cancer screening: a randomised controlled trial. The Lancet 2015;385:1642-52.

27 Howard K, Salkeld GP, Patel MI, et al. Men's preferences and tradeoffs for prostate cancer screening: a discrete choice experiment. Health Expect 2015;18:3123-35. 
28 Hoffman RM, Lewis CL, Pignone MP, et al. Decision-Making processes for breast, colorectal, and prostate cancer screening: the decisions survey. Med Decis Making 2010;30:53-64.

29 McAlearney AS, Reeves KW, Dickinson SL, et al. Racial differences in colorectal cancer screening practices and knowledge within a lowincome population. Cancer 2008;112:391-8.

30 James AS, Daley CM, Greiner KA. Knowledge and attitudes about colon cancer screening among African Americans. Am J Health Behav 2011;35:393-401.

31 Brown DR, Wilson RM, Boothe MAS, et al. Cervical cancer screening among ethnically diverse black women: knowledge, attitudes, beliefs, and practices. J Natl Med Assoc 2011;103:719-28.

32 Jonnalagadda S, Bergamo C, Lin JJ, et al. Beliefs and attitudes about lung cancer screening among smokers. Lung Cancer 2012;77:526-31
33 Silvestri GA, Nietert PJ, Zoller J, et al. Attitudes towards screening for lung cancer among smokers and their non-smoking counterparts. Thorax 2007;62:126-30.

34 Byrne MM, Thurer RJ, Studts JL. Individual decision making about lung cancer screening: a conjoint analysis of perspectives among a high-risk national sample. Cancer Med 2019;8:5779-86.

35 Brenner AT, Malo TL, Margolis M, et al. Evaluating shared decision making for lung cancer screening. JAMA Intern Med 2018;178:1311-6.

36 Dharod A, Bellinger C, Foley K, et al. The reach and feasibility of an interactive lung cancer screening decision aid delivered by patient portal. Appl Clin Inform 2019;10:019-27.

37 National Lung Screening Trial Research Team, Aberle DR, Adams $\mathrm{AM}$, et al. Baseline characteristics of participants in the randomized National lung screening trial. J Natl Cancer Inst 2010;102:1771-9. 